\title{
MÉTODO DE PRÉ-CONCENTRAÇÃO E DETERMINAÇÃO DE 17ß- ESTRADIOL: TESTE DE NOVO SORVENTE
}

\author{
Samara Oliveira Sacht ${ }^{1}$ \\ Anísio M. de Faria ${ }^{2}$ \\ Marcelo Antônio de Oliveira ${ }^{3}$ \\ Aloísio José Bueno Cotta ${ }^{4}$
}

Resumo: Os métodos de monitoramento ambiental para contaminantes emergentes requerem etapa de preparação das amostras para isolar os analitos de interesse. Para tal, a técnica de extração em fase sólida (SPE) é a mais utilizada em conjunto com determinações por técnicas cromatográficas. Este trabalho descreve o desenvolvimento de um método analítico para a determinação da presença e medição das concentrações de um contaminante emergente de ampla ocorrência, o estrogênio 17ß-estradiol. Nesta investigação foi testado o uso de um novo sorvente, de hidrofobicidade reduzida, produzido pela imobilização térmica do poli(dimetilsiloxano-co-alquilmetilsiloxano) sobre partículas de sílica, Si(PDAS), resultando uma menor hidrofobicidade. Com a metodologia desenvolvida usando o novo sorvente obteve-

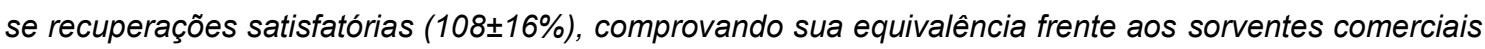
utilizando um único solvente de baixo custo (metanol) na eluição.

Palavras-chave: Contaminantes emergentes; Extração em fase sólida; Cromatografia líquida.

\footnotetext{
1 Engenharia Química/CEUNES-UFES, Brasil. E-mail: Samaraoliveiraeq@gmail.com.

2 UFU-campus Pontal/Química, Faculdade de Ciências Integradas do Pontal, Brasil. E-mail: anizio@ufu.br.

${ }^{3}$ CEUNES-UFES/Departamento de Ciências da Saúde, Brasil. E-mail: marcelo.oliveira@ufes.br.

${ }^{4}$ CEUNES-UFES/Departamento de Ciências Naturais, Brasil. E-mail: aloisio.cotta@ufes.br.
} 